Original article (short paper)

\title{
Concurrent validation of the MABC-2 Motor Tests and MABC-2 Checklist according to the Developmental Coordination Disorder Questionnaire-BR
}

\author{
Renata Capistrano \\ Elisa Pinheiro Ferrari \\ Luciano Portes de Souza \\ Thais Silva Beltrame \\ Fernando Luiz Cardoso \\ State University of Santa Catarina, Florianópolis, SC, Brazil
}

\begin{abstract}
The Movement Assessment Battery for Children, 2nd Ed (MABC-2), comprised of motor tests and a questionnaire (Checklist), has been used by several nationalities to identify problems in children's motor behavior. However, the level of agreement between the motor tests and the checklist has been questioned. So, this study aimed to test the level of competition between the MABC-2 motor test and MABC-2 Checklist, controlled by the Developmental Coordination Disorder Questionnaire (DCDQ-BR) as the gold reference. Parents of 40 children and 16 teachers responded to the MABC-2 Checklist and the DCDQ-BR. Later 40 children were evaluated using the MABC-2 motor test. No significant congruence among a comparison of the MABC-2 motor tests, MABC-2 Checklist and DCD$\mathrm{Q}-\mathrm{BR}$ was observed. The results indicated that there is no concurrent validity between the MABC-2 motor tests and the DCDQ-BR test, whereas the MABC-2 Checklist showed low levels of concurrent validity with the DCDQ-BR. Keywords: validation, MABC-2, MABC-2 Checklist, DCDQ-BR
\end{abstract}

Resumo - "Validação concorrente do MABC-2 testes motores e MABC-2 Checklist de acordo com o DCDQ-BR." A Movement Assessment Battery for Children, $2^{\mathrm{a}}$ ed. (MABC-2), composta por testes motores e um questionário (Checklist) tem sido utilizada em várias nacionalidades para identificar problemas motores de crianças. Entretanto, o nível de concordância entre os testes motores e o Checklist tem sido questionado. Assim, este estudo teve como objetivo testar o nível de concorrência entre o MABC-2 testes motores e MABC-2 Checklist, controlado pelo Developmental Coordinatiom Disorder Questionnaire (DCDQ-BR) como referência ouro. Os pais de 40 crianças e 16 professores responderam o MABC-2 Checklist e DCDQ-BR. Posteriormente 40 crianças foram avaliadas pelo MABC-2. Ao comparar o MABC-2 testes motores, MABC-2 Checklist e o DCDQ-BR, não observamos uma congruência significativa. Ou seja, os resultados indicaram que não houve validade concorrente entre o MABC-2 testes motores e o DCDQ-BR, enquanto que para o MABC-2 Checklist foram observados níveis fracos de validade concorrente com o DCDQ-BR.

Palavras-chave: validação, MABC-2, MABC-2 Checklist, DCDQ-BR

Resumen - "Validación concurrente de las pruebas motoras y lista de chequeo del MABC-2 de acuerdo con el DCDQ-BR." La Movement Assessment Battery for Children, $2^{\mathrm{a}}$ ed. (MABC-2), compuesta de testes motores y un cuestionario (Checklist), se ha utilizado en varios países para identificar problemas motores de los niños. Sin embargo, el nivel de concordancia entre las tareas motoras y el checklist ha sido cuestionado. Así, este estudio tuvo como objetivo evaluar el nivel de concurrencia entre las tareas motoras del MABC-2 y el Checklist del MABC-2, controlados por el instrumento Developmental Coordinatiom Disorder Questionnaire (DCDQ -BR) como patrón oro. Los padres de 40 niños y 16 profesores respondieron al MABC-2 Checklist y al DCDQ-BR. En seguida, 40 niños fueron evaluados con el MABC-2. Comparando las tareas del MABC-2, el checklist del MABC-2 y el DCDQ-BR no se observó congruencia significativa. Es decir, los resultados indicaron que no hubo validez concurrente entre las tareas motoras del MABC-2 y del DCDQ-BR, mientras que para la lista de verificación MABC-2 fueron observados bajos niveles de validez concurrente con el DCDQ-BR.

Palabras claves: validez, MABC-2, MABC-2 Checklist, DCDQ-BR 
Several already established test protocols seek to evaluate the motor development of children in order to identify the possibility of having some motor problems, among which the Movement Assessment Battery for Children Second Edition - MABC-2 excels (Henderson \& Sugden, 1992).

The MABC-2 was developed for children in the UK and has been widely used in many countries around the world, such as Australia (Davis, Ford, Anderson, \& Doyle, 2007; Straker et al., 2011), Norway (Vedul-Kjelsås, Sigmundsson, Stensdotter, \& Haga, 2012), Holland (Jelsma, Geuse, Klerks, Nieimeijer, \& Smits-Engelsman, 2013; Kieviet et al., 2012), the United States (Liu \& Breslin, 2013), Nepal (Buckley et al., 2013), Israel (Engel-Yeger, \& Kasis, 2010; Liberman, Ratzon, \& Bart, 2013), China (Tsang, Guo, Fong, Mak, \& Pang, 2012; Wuang, Su, \& Su, 2012), Canada (Jarus, LourieGelberg, Engel-Yeger, \& Bart, 2011; Silman, Cairney, Hay, Klentrou, \& Faught, 2011), South Africa (Ferguson, Jelsma, Jelsma, \& Smits-Engelsman, 2013) and Brazil (Cardoso \& Magalhães, 2012; Miranda, Beltrame, \& Cardoso, 2011; Santos \& Vieira, 2013; Silva \& Beltrame, 2013; Silva, Contreira, Beltrame, \& Sperandio, 2011).

The MABC- 2 consists of motor tests and the Checklist protocol. The motor tests comprise three sets of tasks, manual dexterity, ball skills and balance (static and dynamic) appropriate for the different groups of ages (Henderson, Sugden, \& Barnett, 2007). The MABC-2 Checklist protocol consists of a questionnaire comprised of questions about child's motor behavior in different everyday situations of life, as in the classroom, recreational and physical education activities and as in everyday situations of personal care. This instrument can be applied by parents or professionals who work directly with children (teachers, doctors, therapists, etc.) together or independent of battery motor testing application (Henderson et al., 2007).

In addition to the MABC- 2 tests (motor tests and Checklist), other instruments existed for detecting children with developmental coordination disorder (DCD) and can be considered the gold standard in this area. Among them we highlight the Developmental Coordination Disorder Questionnaire (DCDQ) developed for children age 5 to 15 by Wilson, Dewey, and Campbell (1998), which was validated in many countries such as: Australia (Civetta \& Hillier, 2008), China (Tseng, Fu, Wilson, \& Hu, 2010), Japan (Nakai et al., 2011), France (Martini, St-Pierre, \& Wilson, 2011), Germany (Kennedy-Behr, Wilson, Rodger, \& Mickan, 2013) and Brazil (Prado, Magalhães, \& Wilson, 2009). The DCDQ is an ordinary questionnaire composed of fifteen items divided into three groups: motor control during movement, fine motor writing and general motor behavior, which evaluate a child's performance in different situations of daily life.

Studies in the motor development's area have investigated the association between the MABC-2 tests (motor tests and Checklist) and the DCDQ, for example, MABC Motor test and MABC Checklist or MABC Motor test and DCDQ (Junaid, Harris, Fulmer, \& Carswell, 2000; Hua, Wu, Gu, \& Meng, 2012; Schoemaker, Niemeijer, Flapper, \& Smit-
s-Engelsman, 2012). In Canada Junaid, Harris, Fulmer, and Carswell (2000) did not find a good correlation among the results of the motor tests of children and the responses from teachers found on the Checklist. In Holland Schoemaker, Niemeijer, Flapper, and Smits-Engelsman (2012) investigated the validity and reliability of the MABC-2 Checklist controlled by the DCDQ in children from 6 to 11 years old and they found a good reliability. The authors recommend the use of the MABC Checklist as a good alternative to identify children with motor difficulties. In China, Hua et al. (2012) evaluated 1.823 children with the MABC motor test and DCDQ. The authors concluded that the MABC has a good reliability and validity. In Brazil no study about the concurrency the MABC-2 motor test and MABC-2 Checklist controlled by the DCDQ was found.

Considering the lack of similar studies in Brazil and the necessity of having a valid and reliable Portuguese tool that can identify children with motor problems, we decided to test the level of concurrency between the MABC- 2 motor tests and the MABC-2 Checklist, controlled by the DCDQ-BR as the supposed gold reference in this field of study.

\section{Method}

\section{Study characteristics}

This study was realized based on a data bank from a project named "Validação do Movement Assessment Battery for Children - Second Edition - Checklist para a Língua Portuguesa" [Validation of the Movement Assessment Battery for Children - Second Edition - Checklist for the Portuguese language]. The protocol number of this study at Santa Catarina State University's Human Research Ethics Committee is $n^{\circ} 171 / 2011$.

\section{Participants}

This study initially invited three levels of participants: 100 school children between 7 and 10 years old, at least one parent or guardian of each child and all schoolteachers that were currently working with these children in Florianópolis, $\mathrm{SC}$, Brazil. Considering the low instrument return rate, only 40 children's parents or their guardians and only 14 children's classroom teachers and 2 physical education teachers correctly filled out the questionnaires. Therefore, only 40 out of 100 children effectively took part in this study: 20 boys with an average age of 8.93 years $(\mathrm{SD} \pm 1.22)$ and 20 girls with an average age of 9.04 years $(\mathrm{SD} \pm 1.00)$. All the participants signed the Term of Free and Informed Consent (TCLE).

As inclusion criteria for the MABC's motor tests were considered: to be 7 through 10 years old; to agree in participate in the study; do not have physical problem that prevented motor assessments performance; and to have the TCLE signed by parents or guardians authorizing participation in the study. 


\section{Instruments}

\section{Movement Assessment Battery for Children - MABC Motor Test}

The MABC-2 is a testing protocol developed by Henderson and Sugden (1992) to evaluate the motor performance of children from ages 3 to 16 years old, divided into two independent parts: a motor skills test and a Checklist questionnaire that have been used to identify children with movement difficulties.

The MABC-2 motor test is a standardized test and the motor evaluation involves the child directly performing a set of divided tasks for specific age groups: age group 1 (3-6 years), age group 2 ( $7-10$ years) and age group 3 (11-16 years). The motor tests seek to evaluate the skills of manual dexterity, ball skills and dynamic and static balance. Although the skills tested are the same for both age groups, each age group has different tasks, each one with the appropriate levels of complexity providing qualitative information about how the child performs and approaches the task.

The test categorizes children according to the level of motor difficulties. The standard scores vary from 1 to 19 and for each value there is a correspondent percentile that can vary from $0.1 \%$ to $99.9 \%$. The values are distributed in the way that values similar or lower than the fifth percentile indicate a significant motor difficulty; between the sixth and the fifteenth percentile indicates risk of motor difficulty; and similar or above of the sixteenth percentile indicate no motor difficulties.

\section{Movement Assessment Battery for Children - Second Edition-Checklist}

The MABC-2 Checklist was created by Henderson et al. (2007) as a part of a complete package designed specifically to help professionals responsible for helping children with movement difficulties. It was developed to identify children who seem to have difficulty moving. This is done based on a list of specific motor behaviors that can be observed in daily life in places such as a classroom or a playground (e.g., buttoning clothing in a fast way, cutting with scissors, catching a ball, etc.). A total of 43 questions involving daily life situations are used to assess a child's motor performance. The performance of the child on each item of the Checklist is evaluated by an adult observer in terms of how efficient it runs, being graded on a Likert scale that describes "Not at all" (0), "some" (1) and "high" (3). This score is summed up to provide a total score, which is then mapped into a "Traffic Light" system showing where the child falls within the normal parameters of the expected age (green zone), shows a delay or some minor movement problems that need to be monitored (amber zone) or has serious problems with movements (red zone).

In this study, we opted for the MABC-2 Checklist to be completed by parents, classroom teachers and physical education teachers, in order to investigate which of the three groups express better sensibility in the evaluation of child's motor behavior.

\section{Developmental Coordination Disorder Questionnaire $(D C D-Q)$}

The DCDQ is a questionnaire created by Wilson et al. (1998) specifically for the detection of DCD in children ages 5 through 15 years. In a more recent version of this questionnaire, used in this study, only 15 items that evaluate children's performance in different situations of daily life were contemplated.

Parents must complete the questionnaire and the questions are divided into three groups: control during movement, fine writing and general motor coordination. Wilson et al. (1998) claim that questionnaires for parents can provide qualitative information about skills and needs of the child in the family environment since parents are the people who spend most of the day with the child. The items describe typical performance in various activities and are scored on a Likert scale of five points ranging from "nothing like your child" (score 1) to the description "extremely like your child" (score 5).

\section{Fieldwork procedures}

In the period before starting the fieldwork evaluations there was a training and standardization of evaluation procedures for the evaluators: they were members of the Laboratory of Disorders of Learning and Development (LADADE-CEFID-UDESC). For the evaluations the institution provided a wide room with free space that enabled the fulfillment of the entire protocol in the same place reducing possible interference with the test.

Each participant was evaluated individually and initially their body mass index and physical height was measured using the Tanita ${ }^{\circledR}$ weight scale with digital resolution and Cescorf ${ }^{\mathbb{B}}$ stadiometer with a resolution of $0.1 \mathrm{~cm}$. After the physical measurements the MABC-2 motor test for the evaluation of manual dexterity, ball skills and balance was applied. The evaluations were conducted in the period between August and December of 2011, during school hours Monday through Friday from 13:00 to 17:30 at the educational institution where the subjects were contacted.

To identify students with some motor difficulties a copy of the MABC-2 Checklist Brazilian version and a copy of the instrument DCDQ were delivered to children's responsible together with a specific consent term. Attached to the questionnaires was an explanatory letter on how to fill out the instrument, as well as different possible ways to communicate with the researchers in case of a need for clarification (via phone, email or in person). The return of completed questionnaires was conducted jointly with the letter of acceptance for participation in the study, collected directly from the subjects.

\section{Statistical analyses}

The statistical analyses only included children's data from parents and teachers that congenially filled out the MABC-2 Checklist and DCDQ questionnaires. To characterize the data descriptive statistics were used the mean and standard deviation. To check the construction validity the one-way ANOVA test was 
applied, which assessed the degree of variance between measures of motor evaluation MABC-2 test with measurements obtained by the MABC-2 Checklist controlled by the DCDQ. The Spearman correlation between MABC-2 motor tests and MABC-2 Checklist also was used. The reference values for this analysis were: below .40, weak correlation; between .40 to .60 , moderate correlation; between .60 to .80 , good correlation; and above .80 , very good correlation (Fayers \& Machin, 2007; McDowell \& Neweel, 1996).

To check the degree of internal consistency of the scale items a reliability analysis was used with Cronbach's alpha coefficient. All data were tabulated and analyzed using the software SPSS 18.0 for Windows with a significance level of $p<.05$.

\section{Results}

Details of participants can be seen in Table 1, in which the children's data are presented in terms of mean and standard deviation according to sex.

Table 1. School children's characterization regarding age and body mass index.

\begin{tabular}{lll}
\hline Variable & $\begin{array}{l}\text { Boys } \\
\text { X(DP) }\end{array}$ & $\begin{array}{l}\text { Girls } \\
\text { X(DP) }\end{array}$ \\
\hline Age (years) & $8.9( \pm 1.2)$ & $9.0( \pm 1.0)$ \\
Weight $(\mathrm{Kg})$ & $18.3( \pm 34.3)$ & $22.7( \pm 34.8)$ \\
Height $(\mathrm{cm})$ & $115.0( \pm 137.7)$ & $124.0( \pm 138.5)$ \\
BMI $\left(\mathrm{Kg} / \mathrm{m}^{2}\right)$ & $13.5( \pm 17.8)$ & $14.8( \pm 18.2)$ \\
\hline
\end{tabular}

$\mathrm{BMI}=$ Body Mass Index.

Figures 1 and 2 refer to the identification of study participants with "defined motor problems," "at risk" or "normal development" identified by their classroom teachers, physical education teachers and parents through the MABC-2 Checklist and represents the results of $\mathrm{MABC}-2$ motor test and DCDQ-BR. In the evaluation made by classroom teachers through the MABC-2 Checklist $70.2 \%$ of subjects were identified as "normal development," $10.6 \%$ were classified as "at risk" and $19.2 \%$ as "defined motor problems." The physical education teachers identified $78.9 \%$ of the children with "normal development," $15.8 \%$ were classified as "at risk" and only $5.3 \%$ were identified as "defined motor problems."

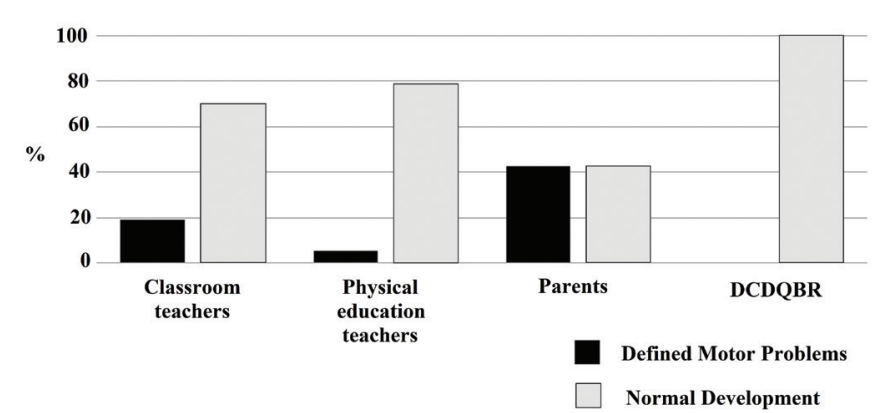

Figure 1. Classification of the children's motor development using the MABC-2 Checklist according to the DCDQBR.

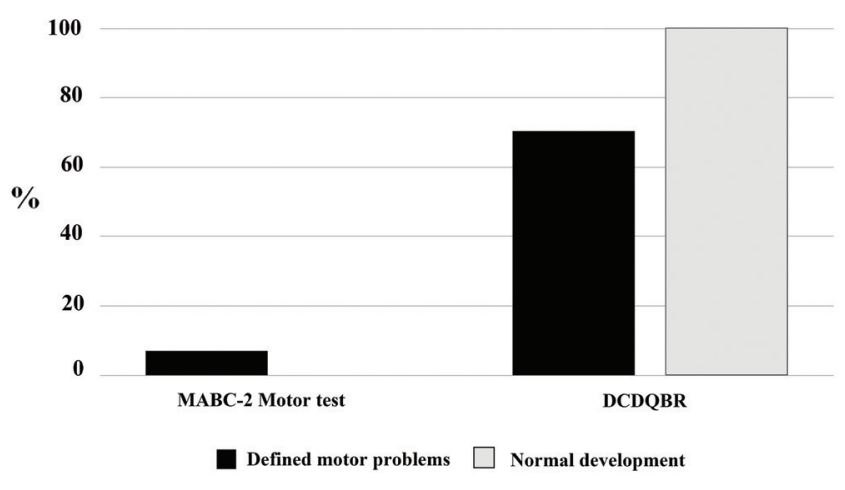

Figure 2. Classification of the children's motor development using the MABC-2 motor test according to the DCDQBR.

According to the children's parents or guardians, $42.5 \%$ of the children were identified as having "normal development," $15.0 \%$ were classified as "at risk" and $42.5 \%$ as having "defined motor problems."

The post hoc Tukey test confirmed that there was no significant difference between judgment of the motor behavior of school children conducted by parents and classroom teachers $(p=.24)$; but when comparing parents and teachers of physical education there was a statistically significant difference $(p=.01)$. When comparing classroom teachers and physical education teachers there was a statistically significant difference again $(p=.038)$. However, the difference is smaller when it was compared parents and classroom teachers.

With regard the DCDQ-BR questionnaire, filled out by legal guardians, results showed that all students (100.0\%) were classified as "probably without DCD" (Figure 1).

When we observe data from the concurrent analyses between the MABC-2 motor tests, MABC-2 Checklist and DCDQ-BR, a statistically significant difference was evident between tests $\left(F_{4,3}\right.$ $=810.1 ; p=.001)$. Post hoc Tukey tests revealed a significant difference among tests of motor assessment of the MABC-2, DCDQ and MABC-2 Checklist questionnaires answered by parents and teachers $(p=.001)$.

The correlations between the MABC- 2 motor test and the MABC-2 Checklist with the DCDQ-BR are presented in the Table 2. We can see a significant negative correlation between the MABC-2 Checklist answered by the parents with the DCDQ-BR.

Table 2. Spearman correlation coefficient.

\begin{tabular}{lcc}
\hline MABC - 2 & DCDQ-BR & $\boldsymbol{p}$-value \\
\hline MABC - 2 Motor Test (total score) & 0.09 & .51 \\
MABC - 2 Motor Test (pattern score) & 0.07 & .65 \\
$\begin{array}{l}\text { MABC - 2 Checklist } \\
\text { (classroom teacher evaluation) }\end{array}$ & -0.28 & .11 \\
$\begin{array}{l}\text { MABC - 2 Checklist } \\
\text { (physical teacher evaluation) }\end{array}$ & 0.16 & .53 \\
$\begin{array}{l}\text { MABC - 2 Checklist } \\
\text { (parent and guardian evaluation) }\end{array}$ & -0.48 & .01 \\
\hline
\end{tabular}




\section{Discussion}

In the application of the MABC-2 Checklist differences were identified in the assessment of children's motor performance made by classroom teachers, parents and physical education teachers. Junaid et al. (2000) conducted a study with 47 children seven to eight years old in a public school in Manaus by comparing the evaluations conducted by classroom teachers and physical education teachers and they concluded that teachers of physical education carried out the most reliable evaluations. Contributing to the findings of the above study, Silva, Dantas, and Cattuzzo (2006) investigated the evaluation of classroom teachers regarding motor performance of children of eight and nine years old, accompanied by physical education teachers. This study demonstrated that the MABC-2 Checklist is valid to identify children with motor problems, but for a more efficient evaluation a collaborative effort between classroom and physical education teachers is required.

These differences in outcome of evaluators can be explained by different issues of the instrument construction (Pasquali, 2009). The first aspect would be the level of understanding and perception of human movement of each group of evaluators, it is expected that physical education professionals be more judicious than classroom teachers and laymen people, respectively. The second issue concerns the context of the task, or motor behavior. It is expected that some tasks are performed more in family life and at home than at school. Thus favoring the assessment of parents in this task and the reverse is also true. Thirdly we must consider the isomorphism, i.e., some tasks can evaluate more than a single motor ability, influencing thus the assessment of the task or motor behavior as a whole.

Regarding the classification of motor performance by applying the three instruments examined in this study, MABC-2 motor test, MABC-2 Checklist and DCDQ, a lack of agreement regarding the percentage of individuals considered to have a typical pattern of motion behavior was found. There were discrepancies in the evaluation obtained by the MABC-2 Checklist and the MABC-2 motor tests, besides their higher prevalence of motor problems compared to the DCDQ. These results join other studies such as Junaid et al. (2000) using the MABC-2 and the MABC Checklist motor test in a group of 103 children. They found a low correlation between the instruments analyzed. The same happened with Pannekoek, Rigoli, Piek, Barret, and Schoemaker (2012) when they compared motor performance applying the MABC motor test and the DCDQ test with teenage scholars.

These differences can be explained by inherent psychometric aspects of the instrument, such as: a) the lack of appropriate and specific questions for each group of evaluators, for example, each question should be adapted and specialized to the social reality of the physical education teachers, classroom teachers and parents or guardians; b) behavioral conduct regarded as a benchmark to assess the movement of these children that are not the best choices because of the complex structure of each motor behavior; and c) finally, the motor behaviors chosen to compose the instrument, that can evaluate more than one motor ability. Besides this the instruments do not have variability that allows a gradual classification of these children by their close informants. This would be a strong indication of the lack of reliability and sensibility of these instruments.

Another aspect concerning this work refers, to the lack of a congruent relationship between the total score of the MABC-2 motor test and MABC-2 Checklist with the DCDQ. Being that, the only correlation found in this study it was between the DCDQ and MABC-2 Checklist completed by parents, being of low magnitude and in the opposite direction to what makes the situation still worst.

A statistically significant correlation of low magnitude and the opposite direction between the score of the MABC-2 Checklist completed by parents and the DCDQ questionnaire indicates that the higher score on the MABC-2 Checklist will be the lowest on the DCDQ. This antagonism differs from findings in other studies that correlate to previous versions of the DCDQ and MABC in younger children, and which found positive and moderate correlations between the two instruments (Civetta \& Hillier, 2008; Schoemaker et al., 2012). The absence of identified participants with motor problems according to the DCDQ may explain the lack of correlation between the instruments in this study.

The main limitation of the study refers to the low number of participants that restricting the extrapolation of data. This limitation can be explained by the low motivation of teachers to fill our instruments due to overwork at school.

\section{Conclusion}

According to the study's results, we can conclude that the evaluation of children's motor performance applying the MABC-2 Checklist differed according to the respondent group. In addition, there was no agreement on the presence or absence of motor problems using the three instruments simultaneously (MABC-2 motor test, MABC-2 Checklist and DCDQ). Finally, there was no agreement between scores from the assessment with the MABC-2 motor test and the DCDQ, since the scores of the DCDQ and the Checklist were low and reversed. Considering this incongruent approach of the instruments investigated in our convenient sample, we suggest that the instruments should be used in a complementary way in order to offer a more complete assessment of children's motor performance.

Therefore, it is suggested that the main instruments of motor evaluation in the process of creation and validation or revalidation should be tested in terms of construct, where the level of isomorphism between the purpose of the instrument and its constituent items are checked. It is suggested that attempts to assess the behavior pathways for motor tasks or motor behaviors departing from more robust theoretical assumptions and a more empirical selection of its constituent items initially analyzing the variability of each item for different target social groups be implemented.

\section{References}

Buckley, G.J., Murray-Kolb, L.E., Khatry, S.K., Leclerq, S.C., Wu, L., West, K.P., \& Christian, P. (2013). Cognitive and motor skills in school-aged children following maternal vitamin A supplementa- 
tion during pregnancy in rural Nepal: A follow-up of a placebocontrolled, randomised cohort. BMJ Open, 3(5). doi: 10.1136/ bmjopen-2012-002000

Cardoso, A.A., \& Magalhães, L.C. (2012). Criterion validity of the Motor Coordination and Dexterity Assessment: MCDA for 7- and 8-years old children. Revista Brasileira de Fisioterapia, 16, 16-22.

Civetta, L.R., \& Hillier, S.L. (2008). The developmental coordination disorder questionnaire and movement assessment battery for children as a diagnostic method in Australian children. Pediatric Physical Therapy, 20, 39-46. doi: 10.1097/PEP.0b013e31815ccaeb

Davis, N.M., Ford, G.W., Anderson, P.J., \& Doyle, L.W. (2007). Developmental coordination disorder at 8 years of age in a regional cohort of extremely-low-birthweight or very preterm infants. Developmental Medicine and Child Neurology, 49, 325-330.

Engel-Yeger, B., \& Kasis, A. H. (2010). The relationship between developmental co-ordination disorders, child's perceived self-efficacy and preference to participate in daily activities. Child: Care, Health and Development, 36, 670-677. doi:10.1111/j. 1365-2214.2010.01073.x

Fayers, P.M., \& Machin, D. (2007). Quality of life: Assessment, analysis and interpretation (2nd ed.). New York, NY: John Wiley \& Sons.

Ferguson, G.D., Jelsma, D., Jelsma, J., \& Smits-Engelsman, B.C.M. (2013). The efficacy of two task-orientated interventions for children with developmental coordination disorder: Neuromotor task training and Nintendo Wii Fit training. Research in Developmental Disabilities, 34, 2449-2461.

Henderson, S.E., \& Sugden, D.A. (1992). Movement Assessment Battery for Children-MABC. London: Psychological Corporation.

Henderson, S.E., Sugden, D.A., \& Barnett, A.L. (2007). Movement Assessment Battery for Children Second Edition. London: Psychological Corporation.

Hua, J., Wu, Z.C., Gu, G.X., \& Meng, W. (2012). Assessment on the application of 'Movement Assessment Battery' for Children. Zhonghua Liu Xing Bing Xue Za Zhi, 33, 1010-1015.

Jarus, T., Lourie-Gelberg, Y., Engel-Yeger, B., \& Bart, O. (2011). Participation patterns of school-aged children with and without DCD. Research in Developmental Disabilities, 32, 1323-1331. doi: 10.1016/j.ridd.2011.01.033

Jelsma, L.D., Geuze, R.H., Klerk, M.H., Niemeijer, A., \& Smits-Engelsman, B.C.M. (2013). The relationship between joint mobility and motor performance in children with and without the diagnosis of developmental coordination disorder. BMC Pediatrics, 13(35). doi:10.1186/1471-2431-13-35

Junaid, K., Harris, S.R., Fulmer, K.A., \& Carswell, A. (2000). Teachers' use of the MABC Checklist to identify children with motor coordination difficulties. Pediatric Physical Therapy, 12, 158-163.

Kennedy-Behr, A., Wilson, B.N., Rodger, S., \& Mickan, S. (2013). Cross-cultural adaptation of the Developmental Coordination Disorder Questionnaire 2007 for German-speaking countries: DCDQ -G. Neuropediatrics, 44, 245-251. doi: 10.1055/s-0033-1347936

Kieviet, J.F., Oosterlaan, J., van Zwol, A., Boehm, G., Lafeber, H.N., \& van Elburg, R.M. (2012). Effects of neonatal enteral glutamine supplementation on cognitive, motor and behavioural outcomes in very preterm and/or very low birth weight children at school age. British Journal of Nutrition, 108, 2215-2220. doi: http://dx.doi. org/10.1017/S0007114512000293

Liberman, L., Ratzon, N., \& Bart, O. (2013). The profile of performance skills and emotional factors in the context of participation among young children with developmental coordination disorder. Research in Developmental Disabilities, 34, 87-94. doi: http:// dx.doi.org/10.1016/j.ridd.2012.07.019

Liu, T., \& Breslin, C.M. (2013). The effect of a picture activity schedule on performance of the MABC-2 for children with autism spectrum disorder. Research Quarterly for Exercise and Sport, 84, 206-212.
Martini, R., St-Pierre, M.F., \& Wilson, B.N. (2011). French Canadian cross-cultural adaptation of the Developmental Coordination Disorder Questionnaire '07: DCDQ-FC. Canadian Journal of Occupational Therapy, 78, 318-327.

McDowell, I., \& Neweel, C. (1996). Measuring health: A guide to rating scales and questionnaires (2nd ed.). New York, NY: Oxford University Press.

Miranda, T.B., Beltrame, T.S., \& Cardoso, F.L. (2011). Desempenho motor e estado nutricional de escolares com e sem transtorno do desenvolvimento da coordenação. Revista Brasileira de Cineantropometria e Desempenho Humano (Impresso), 13, 59-66. doi: 10.5007/1980-0037.2011v13n1p59

Nakai, A., Miyachi, T., Okada, R., Tani, I., Nakajima, S., Onishi, M., ... Tsujii, M. (2011). Evaluation of the Japanese version of the Developmental Coordination Disorder Questionnaire as a screening tool for clumsiness of Japanese children. Research in Developmental Disabilities, 32, 1615-1622. doi: 10.1016/j.ridd.2011.02.012

Pannekoek, L., Rigoli, D., Piek, J., Barrett, N., \& Schoemaker, M. (2012). The revised DCDQ: Is it a suitable screening measure for motor difficulties in adolescents? Adapted Physical Activity Quarterly, 29, 81-97.

Pasquali, L. (2009). Psychometrics: Test theory in psychology and education (3rd ed.). Petrópolis, RJ: Vozes.

Prado, M.S.S., Magalhães, L.C., \& Wilson, B.N. (2009). Cross-cultural adaptation of the Developmental Coordination Disorder Questionnaire for Brazilian children. Revista Brasileira de Fisioterapia, 13, 236-243.

Santos, P.V.A., \& Vieira, L.J.L. (2013). Prevalência de desordem coordenativa desenvolvimental em crianças com 7 a 10 anos de idade. Revista Brasileira de Cineantropometria e Desempenho Humano, 15, 233-242.

Schoemaker, M.M., Niemeijer, A.S., Flapper, B.C.T., \& Smits-Engelsman, B.C.M. (2012). Validity and reliability of the Movement Assessment Battery for Children-2 Checklist for children with and without motor impairments. Developmental Medicine \& Child Neurology, 54, 368-375. doi: 10.1111/j.1469-8749.2012.04226.x

Schoemaker, M.M., Smits-Engelsman, B.C.M., \& Jongmans, M.J. (2003). Psychometric properties of the Movement Assessment Battery for Children-Checklist as a screening instrument for children with a developmental co-ordination disorder. British Journal of Educational Psychology, 73, 425-331.

Silman, A., Cairney, J., Hay, J., Klentrou, P., \& Faught, B.E. (2011). Role of physical activity and perceived adequacy on peak aerobic power in children with developmental coordination disorder. $\mathrm{Hu}$ man Movement Science, 30, 672-681.

Silva, E.V.A., Contreira, A.R., Beltrame, T.S., \& Sperandio, F.F. (2011). Programa de intervenção motora para escolares com indicativo de transtorno do desenvolvimento da coordenação - TDC. Revista Brasileira de Educação Especial, 17, 137-150. doi: 10.1590/ S1413-65382011000100010

Silva, J., \& Beltrame, S.T. (2013). Indicativo de transtorno do desenvolvimento da coordenação de escolares com idade entre 7 e 10 anos. Revista Brasileira de Ciências do Esporte, 35, 3-14.

Silva, J.A.O., Dantas, L.E., \& Cattuzzo, M.T. (2006). Teste mabc: Aplicabilidade da lista de checagem na região sudeste do Brasil. Revista Portuguesa de Ciência do Desporto, 6, 356-361.

Straker, L.M., Campbell, A.C., Jensen, L.M., Metcalf, D.R., Smith, A.J., Abbott, R.A., ... Piek, J.P. (2011). Rationale, design and methods for a randomised and controlled trial of the impact of virtual reality games on motor competence, physical activity, and mental health in children with developmental coordination disorder. BMC Public Health, 11(654). doi:10.1186/1471-2458-11-654

Tsang, W.W., Guo, X., Fong, S.S., Mak, K.K., \& Pang, M.Y. (2012). Activity participation intensity is associated with skeletal develo- 
pment in pre-pubertal children with developmental coordination disorder. Research in Developmental Disabilities, 33, 1898-1904.

Tseng, M.H., Fu, C.P., Wilson, B.N., \& Hu, F.C. (2010). Psychometric properties of a Chinese version of the Developmental Coordination Disorder Questionnaire in community-based children. Research in Developmental Disabilities, 31, 33-45. doi: 10.1016/j. ridd.2009.07.018

Vedul-Kjelsås, V., Sigmundsson, H., Stensdotter, A.K., \& Haga, M. (2012). The relationship between motor competence, physical fitness and self-perception in children. Child Care Health Development, 38, 394-402. doi: 10.1111/j.1365-2214.2011.01275.x

Wilson, B.N., Dewey, D., \& Campbell, A. (1998). Developmental Coordination Disorder Questionnaire (DCDQ). Canada: Alberta Children's Hospital Research Center.

Wuang, Y.P., Su, J. H., \& Su, C.Y. (2012). Reliability and responsiveness of the Movement Assessment Battery for Children-Second Edition Test in children with developmental coordination disorder. Developmental Medicine \& Child Neurology, 54, 160-165. doi: 10.1111/j.1469-8749.2011.04177.x

\section{Authors' note}

Renata Capistrano and Luciano Portes de Souza have a master's degree in Human Movement Sciences, State University of Santa Catarina (UDESC), Florianópolis (SC), Brazil.

Elisa Pinheiro Ferrari, is a $\mathrm{PhD}$ candidate in Human Movement Sciences, State University of Santa Catarina (UDESC), Florianópolis (SC), Brazil.

Thais Silva Beltrame, $\mathrm{PhD}$, and Fernando Luiz Cardoso, $\mathrm{PhD}$, are associate professors in the Graduate Program in Human Movement Sciences, State University of Santa Catarina (UDESC), Florianópolis (SC), Brazil.

\section{Corresponding author}

Renata Capistrano

Centro de Ciências da Saúde e do Esporte/ Laboratório de Distúrbios da Aprendizagem e do Desenvolvimento. Rua Pascoal Simone, 358, Coqueiros, Florianópolis SC, 88080-350, Brasil.

Phone: +55 (48) 3321-8600

E-mail: recapis@gmail.com

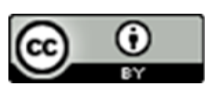

Motriz. The Journal of Physical Education. UNESP. Rio Claro, SP, Brazil - eISSN: 1980-6574 - under a license Creative Commons - Version 3.0 